\title{
Removal of non-palpable etonogestrel implants
}

\author{
Diana Mansour, Martyn Walling, Derek Glenn, Christian Egarter, Olivier Graesslin, Josef Herbst, \\ lan S Fraser
}

\section{Introduction}

This review has been written by a group of specialists who, between them, have accumulated considerable experience with slightly differing approaches to difficult Implanon ${ }^{\circledR}$ (the single-rod, subdermal implant system releasing etonogestrel; NV Organon, Oss, The Netherlands) removals, largely based on precise implant location using specific ultrasound scanning techniques. ${ }^{1-6}$ The surgical techniques used for removal depend on a number of factors including depth and anatomical location of the implant, proximity of other structures, experience of the operator and availability of simultaneous ultrasound scanning.

Most clinicians working in the field of contraception and sexual health will have reasonable conventional surgical skills, but increasing expertise with the correct type of realtime ultrasound scanning transducer will allow a precise interventional radiology-type approach to removal, even of very deep implants through a small incision. ${ }^{7,8}$ This review attempts to place different surgical approaches into a sensible clinical context.

\section{Palpable implants \\ Conventional removal techniques for multi-rod implant systems}

The key to successful contraceptive implant removal is correct insertion. This point cannot be emphasised enough. A number of health care professionals with experience of providing the six-capsule levonorgestrel system, Norplant ${ }^{\circledR}$ (Bayer Schering Pharma, Berlin, Germany), find Implanon removal "a breeze". Perhaps this is because there is just one implant to remove and Implanon is semi-rigid and amenable to the 'pop-out' removal technique. ${ }^{7}$ A small number of

J Fam Plann Reprod Health Care 2008; 34(2): 89-91 (Accepted 12 February 2008)

Contraception and Sexual Health Service, Newcastle upon Tyne Primary Care Trust, Newcastle upon Tyne, UK

Diana Mansour, FRCOG, FFSRH, Consultant in Community Gynaecology

Parkside Surgery, Boston, UK

Martyn Walling, FRCGP, FFSRH, General Practitioner

Department of Radiology, St George Hospital, Sydney,

Australia

Derek Glenn, MBBS, FRANZCR, Director of Radiology

Department of Obstetrics and Gynaecology, University of Vienna Medical School, Vienna, Austria

Christian Egarter, MD, Professor

Department of Obstetrics and Gynaecology, Centre

Hospitalier Universitaire, Reims, France

Olivier Graesslin, MD, Gynaecologist

Department of Obstetrics and Gynaecology, Paracelsus Klinik, Marl, Germany

Josef Herbst, MD, Head of Department

Department of Obstetrics and Gynaecology, University of Sydney, Sydney, Australia

lan S Fraser, MD, FRANZCOG, Professor in Reproductive Medicine

Correspondence to: Dr Diana Mansour, Contraception and Sexual Health Service, Newcastle upon Tyne Primary Care Trust, Graingerville Clinic, Westgate Road, Newcastle upon Tyne NE4 6BE, UK. E-mail: Diana.Mansour@newcastle-pct.nhs.uk

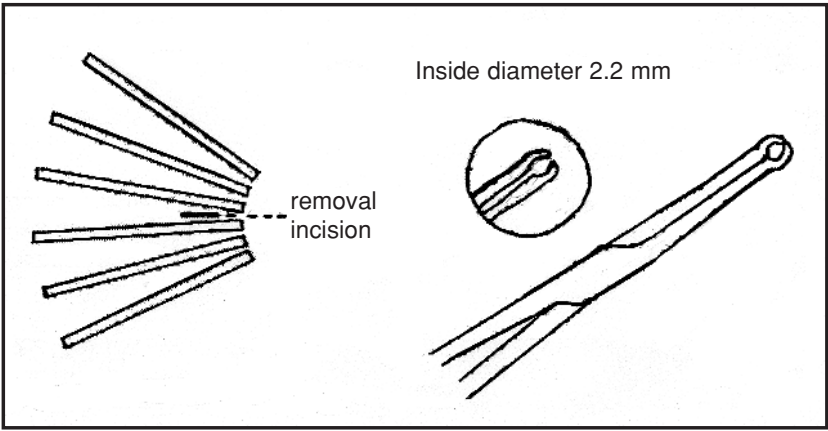

Figure 1 The ' $U$ ' technique for Norplant ${ }^{\circledR}$ removal

clinicians are still removing Norplant implants in Western Europe from migrants and refugees as health projects in subSaharan Africa and elsewhere continue to provide these contraceptives. Jadelle ${ }^{\circledR}$ (the two-rod levonorgestrel system; Bayer Schering Pharma, Berlin, Germany) has just been added to the World Health Organization's list of essential medications and may therefore be encountered more frequently for removal.

The traditional removal technique for Norplant involves a 3-4 mm incision made at the base of the implant 'fan'. Small curved artery/mosquito forceps are used to gently grasp each capsule. The ' $U$ ' technique was developed in the late 1990 s with the incision made between the third and fourth capsules towards the base of the fan. Modified vasectomy forceps are used to grasp each implant (Figure 1). The ' $U$ ' technique is easier to teach, results in quicker removal times, and capsules are less likely to tear or break on removal compared with the classical technique. ${ }^{9-12}$

\section{Removing palpable Implanon implants}

Implanon, a single, semi-rigid rod, makes both implant insertion and removal easier. It is more forgiving than Norplant capsules, rarely tearing when mosquito forceps are applied. 9 The firmer consistency of the Implanon rod enables the remover, under local anaesthetic, to use the 'popout' technique (Figure 2).

After local anaesthetic has been inserted under the distal end of the Implanon rod, a small 2-4 mm incision is made at the tip of the implant with a sharp pointed scalpel blade (Figure 2a). It is important that most of the anaesthetic is injected under the implant as this lifts the rod up, making it visible and easily palpable through the skin. If local anaesthetic is injected over the implant tip then the implant becomes impalpable and the removal process complex.

The implant is gently pushed towards the incision, grasped with mosquito/small artery forceps and removed (Figure 2b). If the implant is encapsulated, the fibrous tissue is dissected from the tip with the forceps/scalpel before the implant is removed (Figure $2 \mathrm{c}$ and $2 \mathrm{~d}$ ). The small incision is closed using steristrips or a butterfly dressing, and a pressure bandage can be applied to help prevent post-removal bruising. 13

Occasionally, although the implant is easily palpable, the tip of the Implanon is not visible at the incision. In this situation all removal practitioners should have the necessary skills to modify their technique and insert the curved mosquito forceps into the incision under the tip of the implant. The forceps should be opened and closed several times around the capsule tip to separate subcutaneous tissue 


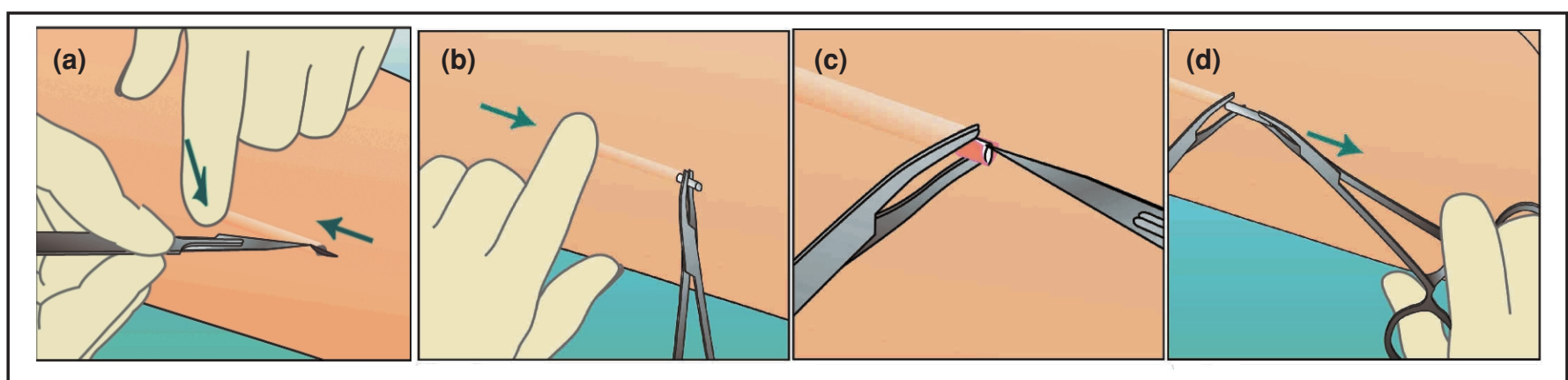

Figure 2 'Pop-out' removal technique with Implanon ${ }^{\circledR}$. (C) NV Organon, Oss, The Netherlands

and then used to grasp the implant. A useful tip is to guide the implant into the mouth of the forceps using a finger of the other hand. The forceps should then be closed. A second forceps/scalpel may be required to clean away any fibrous tissue and finally remove the implant. This technique can also be used when the Implanon is deeper but palpable and the distal end does not readily come to the surface.

Occasionally only part of the implant is palpable. The technique is modified with $2-3 \mathrm{ml}$ of local anaesthetic applied under the palpable portion. A $2-4 \mathrm{~mm}$ incision is made at this point, the subcutaneous tissue dissected with mosquito forceps, and the palpable portion of the implant pushed with a guiding finger into the open mouth of the mosquito forceps. The implant is then brought to the incision, further fibrous tissue dissected with a second forceps, which is also then used to remove the implant.

\section{Non-palpable implants}

\section{Classical surgical approach}

In cases where the Implanon is impalpable or there is doubt about its location, advice should be sought from those experienced in locating and removing non-palpable implants or from the manufacturer. Most 'experts' recommend the use of ultrasound to locate such implants, ${ }^{1-5}$ and fairly basic portable ultrasound machines with high-resolution linear array transducers of 7-15 MHz can be used, though 12-15 MHZ is ideal.

Location of non-palpable implants using ultrasound scanning has previously been described by the present authors. ${ }^{1}$ Once the anatomical position of the implant has been established, the skin is then clearly marked to identify the position of the implant to facilitate removal. The ultrasound probe should be lightly applied in order to reduce errors in 'skin to implant' depth measurements.

The arm is then cleansed and draped with sterile cloths. Many suggest using 1\% lidocaine with 1 in 100000 adrenaline as the local anaesthetic to reduce blood loss and aid visualisation of the implant. A $1.5 \mathrm{~cm}$ longitudinal incision is made between the previously made ultrasound skin markings, normally at the site where the implant is most superficial.

If the implant is located within the subcutaneous tissue, careful blunt dissection is undertaken using small curved artery forceps. When the implant is located, by touch, a modified vasectomy or small mosquito forceps is inserted and the implant grasped, cleaned and removed. Other techniques involve using 'real-time' ultrasound to locate the implant and then directing a small artery forceps or modified vasectomy forceps via a $2-4 \mathrm{~mm}$ incision to grasp the implant. Some practitioners, after locating the implant by ultrasound, make a small $2-4 \mathrm{~mm}$ incision over the most superficial portion and blindly dissect using a small artery forceps until the implant is felt and grasped.

If the implant is more deeply sited under the fascial sheath, within the muscle or the neurovascular bundle, many 'expert removers' use a somewhat longer incision of 1.5-2 $\mathrm{cm}$, followed by blunt dissection and then direct visualisation of the muscle fascia or neurovascular sheath. The availability of an assistant together with the use of small skin retractors is vital (Figure 3). The muscle fascia or sheath is then divided, the muscle fibres or vital structures separated until the implant is located, grasped, cleaned and removed. Great caution needs to be exercised in identifying and avoiding structures in the neurovascular bundle.

The average time duration for removal using any of these techniques is approximately 10 minutes.

\section{Interventional radiology approach}

There are a number of interventional radiologists across the world removing impalpable Implanon using techniques regularly employed in their clinical field.7,8 These practitioners are well practised in using 'real-time' ultrasound to take biopsies or remove 'foreign bodies' ${ }^{6-8}$ A $7-15 \mathrm{MHz}$ (ideally $12-15 \mathrm{MHz}$ ) linear array transducer focused close to the skin, with all computed postprocessing aids turned off, allows precise visualisation of the implant throughout the removal procedure. ${ }^{1}$ The technique has been well described elsewhere. ${ }^{8}$

Utilising interventional radiology skills the clinician injects moderate volumes of local anaesthetic (10-20 ml $1 \%$ lidocaine with 1 in 100000 adrenaline) through a 25gauge needle of $60 \mathrm{~mm}$ length as it is advanced under the implant using direct ultrasound visualisation. ${ }^{8}$ This technique lifts the implant away from underlying structures and has been used for implants within the neurovascular bundle. The needle is advanced under the implant and the needle tip then angled upwards using counter pressure on the skin of the arm with a fingertip placed just below the

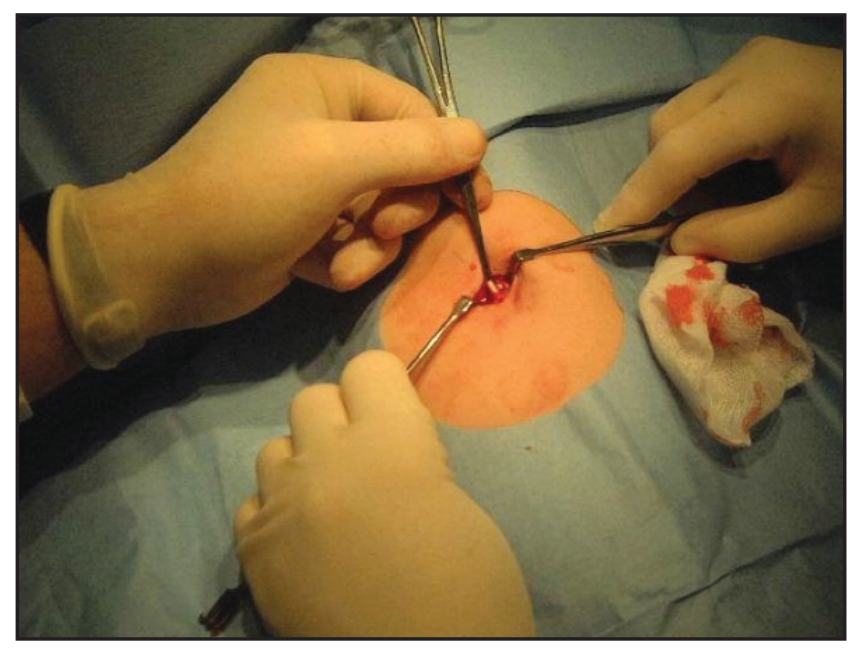

Figure 3 Surgical exposure of a deep-lying implant. Figure reproduced with the kind permission of $M$ Walling 
site at which the tip is due to emerge. Care needs to be taken to ensure that a needle stick injury does not occur. When the tip exits the arm it should be grasped and held in place with an artery forceps. This technique lifts the implant away from important underlying anatomical structures and stabilises it closer to the surface. A small 2-4 $\mathrm{mm}$ incision can then be made directly above the implant (again confirmed by ultrasound guidance) and small curved artery forceps (or alligator forceps) used to dissect down to the implant. The implant is then grasped and removed. 8

\section{Clinical governance issues}

"All patients are entitled to good standards of practice and care from their doctors. Essential elements of this are professional competence, good relationships with patients and colleagues, and observance of professional ethical obligations." This statement from the Faculty of Sexual and Reproductive Healthcare (formerly the Faculty of Family Planning and Reproductive Health Care $)^{14}$ indicates the need for all health care professionals to recognise and work within the limits of their own professional competence. This relates especially to situations that an individual has not encountered previously. Occasionally clinicians have attempted to fit or remove a contraceptive implant (even a deep implant) without the necessary experience and without recognising the potentially serious hazards. There are still a very small number of operators who may cause repeated problems related to deep insertions, 'lost implants' and multiple failed attempts to remove these implants. A number of medico-legal cases attest to this. With more than three million women currently using Implanon worldwide there are few reported complications. In practice, most health care professionals provide excellent care.

A non-palpable implant should always first be localised by either ultrasound scan or magnetic resonance imaging before removal is attempted, and subsequently be removed under the guidance of ultrasound scan. In case of doubt, the presence of Implanon can be verified by the presence of etonogestrel in the serum. The manufacturer should be contacted for further guidance. Exploratory surgery without knowledge of the exact location of the implant is strictly discouraged. Removal of deeply inserted implants should be conducted with caution in order to prevent damage to deeper neural or vascular structures in the arm and should be performed by health care providers familiar with the anatomy of the arm. In most cases, removals of this type are done by gynaecologists or family planning physicians with specific experience or by interventional radiologists.

It is important for all service providers and health care professionals working in the field of contraception to recognise the need for appropriate training, which includes competence to undertake Implanon removal as well as correct insertion.

It must also be remembered that Implanon is a longacting, reversible hormonal contraceptive method that needs a health care professional to initiate and discontinue its use. This puts the onus on the professional to provide sound and balanced clinical advice. Occasionally women feel coerced into continuing with a long-acting method even when they are suffering from troublesome side effects. Perhaps this concern explains the poor uptake of longacting contraceptive methods in some regions and is a particular worry for those women with implants that are difficult to localise.

Despite the clear insertion instructions provided by the manufacturer within the product labelling, removal problems may continue to occasionally arise. Consequently, having an effective and rapidly available expert referral pathway will reduce patient anxiety and potential litigation. In those countries where Implanon is available there are now recognised 'removal' experts in different geographical areas who will accept referrals for complex or difficult cases. The manufacturer of Implanon, NV Organon, holds a list of these clinicians in the countries where Implanon is available, and also supports health care professionals who wish to develop further skills in removal of non-palpable implants for their region. Those individuals undertaking a service for removal of non-palpable implants must maintain their skills and ensure that their medical insurance scheme covers work outside of their employing practice or hospital.

For those providing an 'expert' service there needs to be careful documentation of all cases of non-palpable implants, in particular noting the 'inserting' health care professional and institution. Sometimes a number of incidents involving a single practitioner are reported over time, and having an audit trail will help identify clinicians who need to be made aware of such a scenario. The health care professional who inserted the non-palpable implant should be informed and, if this situation occurs repeatedly, appropriate reporting to their clinical supervisor is strongly advised. Women with non-palpable implants are seen as a 'serious adverse event' by NV Organon, and therefore details of any such incidents should be reported to the manufacturer.

\section{Statements on funding and competing interests}

Funding All the authors have received honoraria and expenses for attendance at advisory boards, lectures or sponsored symposia for Organon.

Competing interests None identified.

\section{References}

1 Mansour D, Fraser IS, Walling M, et al. Methods of accurate localisation of non-palpable subdermal contraceptive implants. $J$ Fam Plann Reprod Health Care 2008; 34: 9-12.

2 Walling M. How to remove impalpable Implanon ${ }^{\circledR}$ implants. $J$ Fam Plann Reprod Health Care 2005; 31: 320-321.

3 Gabriel H, Shulman L, Marko J, Nikolaidis P, Chirita V. Compound versus fundamental imaging in the detection of subdermal contraceptive implants. J Ultrasound Med 2007; 26: 355-359 (erratum in J Ultrasound Med 2007; 26: 1452).

4 Westerway SC, Picker R, Christie J. Implanon implant detection with ultrasound and magnetic resonance imaging. Aust $N Z J$ Obstet Gynaecol 2003; 43: 346-350.

5 Shulman LP, Gabriel H. Management and localization strategies for the nonpalpable Implanon rod. Contraception 2006; 73: 325-330.

6 Singh M, Mansour D, Richardson D. Location and removal of non-palpable Implanon ${ }^{\circledR}$ implants with the aid of ultrasound guidance. J Fam Plann Reprod Health Care 2006; 32: 153-156.

7 James P, Trenery J. Ultrasound localisation and removal of nonpalpable Implanon implants. Aust N Z J Obstet Gynaecol 2006; 46: 225-228.

8 Fraser IS, Glenn D, Mansour D, et al. Localization and removal of non-palpable subdermal contraceptive implants with simultaneous ultrasound guidance and needle stabilization. $A m$ $J$ Roentgenol 2008; (submitted).

9 New Norplant implant removal techniques can make your job easier. Contracept Technol Update 1995; 16: 121-125.

10 Praptohardjo R, Praptohardjo U. ' $U$ ' technique and standard technique of Norplant removal. Adv Contracept 1995; 11: 115-122.

11 Rosenberg MJ, Alvarez F, Barone MA, Waugh MS, Brache V, Pollack AE. A comparison of "U" and standard techniques for Norplant removal. Obstet Gynecol 1997; 89: 168-173.

12 Edwards JE, Moore A. Implanon. A review of clinical studies. $\mathrm{Br}$ J Fam Plann 1999; 24(4 Suppl.): 3-16.

13 Implanon: Summary of Product Characteristics (SPCs). May 2006. Organon Laboratories Ltd, UK. http://emc.medicines. org.uk/emc/assets/c/html/displaydoc. asp?documentid=5382 [Accessed 21 November 2007].

14 Faculty of Family Planning and Reproductive Health Care. Maintaining Good Medical Practice for Those Working in Family Planning and Reproductive Health Care. March 2001. http://www.ffprhc.org.uk/admin/uploads/maintaining.pdf [Accessed 21 November 2007]. 